\title{
Hiperplasia adrenal congênita por deficiência da 21-hidroxilase, forma clássica: estudo da freqüência em famílias de indivíduos afetados
}

\author{
Congenital adrenal hyperplasia due to 21-hydroxylase deficiency, classic form: \\ frequency evaluation of families with affected patients
}

Lucas Ricci Bento', Clarissa Cerchi A. Ramos ${ }^{1}$, Ezequiel Moreira Gonçalves², Maricilda Palandi de Mello

Maria Tereza M. Baptista ${ }^{4}$, Sofia Helena V. de Lemos-Marini ${ }^{5}$, Gil Guerra-Júnior ${ }^{6}$

\section{RESUMO}

Objetivo: Analisar a freqüência de indivíduos afetados e das formas clínicas da doença, de acordo com o gênero e a taxa de consangüinidade, em famílias com hiperplasia adrenal congênita (HAC) por deficiência da enzima 21-hidroxilase, forma clássica (HAC-D21-OHC).

Métodos: A casuística foi composta por 58 famílias com 79 indivíduos afetados (67 vivos e 12 mortos) com pais normais e pelo menos um filho afetado vivo com diagnóstico comprovado da doença. A freqüência de indivíduos afetados foi avaliada pelas técnicas de Haldane e Hogben, com análise por seleção truncada. Também foram avaliadas a história parental de consangüinidade e a freqüência de homozigose de mutações no gene CYP21A2, bem como a forma clínica da doença e a distribuição por gênero.

Resultados: Dez famílias apresentaram história de consangüinidade entre os pais e mais cinco com homozigose no estudo molecular. A freqüência de indivíduos afetados nas irmandades avaliadas foi de $23,5 \%$, semelhanteà esperada de $25 \%$; no entanto, com distribuição heterogênea. Quanto às formas clínicas, $56(70 \%)$ eram perdedores de sal (25M:31F) e 23 (30\%) virilizantes simples (10M:13F), não sendo observada diferença na distribuição entre os gêneros.

Conclusões: Estes dados confirmam que a HAC-D21-OHC apresenta padrão de herança monogênica autossômica recessiva, com freqüência de 23,5\% na irmandade de indivíduos afetados, elevada taxa de consangüinidade e proporção semelhante entre os gêneros, porém com distribuição heterogênea no número de casos nas irmandades e predomínio da forma clínica perdedora de sal.

Palavras-chave: hiperplasia supra-renal congênita; esteróide 21-hidroxilase; genes recessivos; consangüinidade.

\footnotetext{
'Aluno de graduação em Medicina da Faculdade de Ciências Médicas da Universidade Estadual de Campinas (FCM-Unicamp) e bolsista do Programa de Iniciação Científica (Pibic) do Conselho Nacional de Desenvolvimento Científico e Tecnológico (CNPq)

2Professor de Educação Física e mestrando do Curso de Pós-Graduação em Saúde da Criança e do Adolescente da FCM-Unicamp e bolsista da Fundação de Amparo à Pesquisa do Estado de São Paulo (Fapesp)

${ }^{3}$ Livre-docente em Genética Médica e pesquisadora do Centro de Biologia Molecular e Engenharia Genética da Unicamp

${ }^{4}$ Professora doutora colaboradora do Departamento de Clínica Médica da FCM-Unicamp

${ }^{5}$ Professora doutora do Departamento de Pediatria da FCM-Unicamp

Professor livre-docente do Departamento de Pediatria da FCM-Unicamp

e orientador dos alunos
}

\section{ABSTRACT}

Objective: To analyze the frequency of affected patients, rate of parental consanguinity and clinical forms of the disease, according to sex in families with congenital adrenal hyperplasia (CAH) due to 21-hydroxylase deficiency, classic form (CAH-21-OHD-C).

Methods: 58 families with 79 patients (67 alive and 12 dead) with non-affected parents and at least one affected live patient with an established diagnosis of the disease by molecular analysis were studied. The frequency of affected siblings was evaluated according to Haldane and Hogben techniques by truncated selection. Data about parental consanguinity, frequency of CYP21A2 homozygosis gene mutation, clinical form of the disease and sex distribution were also evaluated.

Results: Ten families had parental history of consanguinity and other five had homozygosis in the molecular analysis. The frequency of affected children in the kindred was $23.5 \%$, similar to the $25 \%$ expected, but the sample showed a heterogeneous distribution. Among the clinical forms, 56 $(70 \%)$ patients had the salt wasting form (25 males and 31 females) and $23(30 \%)$ the simple virilizing one (10 males and 13 females) without difference in sex distribution.

Conclusions: These data confirm that CAH-21-OHD-C has an autosomal recessive monogenic inheritance, with a high rate of consanguinity, similar distribution in both sexes, but it has a heterogeneous distribution of cases among the kindred with predominance of the salt wasting form.

Key-words: adrenal hyperplasia, congenital; steroid 21-hydroxylase; genes, recessive; consanguinity.

Endereço para correspondência

Gil Guerra-Júnior

Departamento de Pediatria da FCM-Unicamp

Cidade Universitária Zeferino Vaz, sem número

Caixa Postal 6111 - CEP 13083-970 - Campinas/SP

E-mail: gilguer@fcm.unicamp.br

Recebido em: 21/2/2007

Aprovado em: 26/4/2007

Fonte financiadora: CNPq, com bolsas para os alunos de iniciação científica e Fapesp, com bolsa de mestrado 


\section{Introdução}

A hiperplasia adrenal congênita (HAC) é um erro inato do metabolismo do cortisol e, em mais de $90 \%$ dos casos, causada pela deficiência da enzima 21-hidroxilase (D21$\mathrm{OH})$. Trata-se de um dos erros inatos do metabolismo mais freqüentes nos seres humanos. O bloqueio enzimático na esteroidogênese adrenal acarreta diminuição da concentração sérica de cortisol e conseqüente aumento da liberação de hormônio adenocorticotrófico (ACTH) e hormônio liberador de corticotrofina (CRH), pela redução do retrocontrole negativo, e, sendo assim, produz um estímulo exagerado do córtex adrenal na tentativa de alcançar as concentrações ideais de cortisol no organismo. Como conseqüência desse processo, ocorre a hiperplasia das adrenais e o acúmulo dos compostos pré-bloqueio enzimático, assim como a deficiência dos compostos pós-bloqueio ${ }^{(1-6)}$.

Dependendo da população estudada e dos métodos de diagnóstico, sua freqüência atinge de 1 em 10.000 a 1 em 15.000 nascimentos $^{(7)}$. A HAC por D21-OH encontra-se classificada no Catálogo de Doenças Mendelianas Humanas (OMIM 201910) como uma doença monogênica de herança autossômica recessiva, sendo $25 \%$ o risco de recorrência na irmandade ${ }^{(8)}$.

A doença pode apresentar-se em duas formas clínicas: clássica, subdividida em perdedora de sal e virilizante simples; e não clássica, subdividida em críptica e tardia ${ }^{(1-}$ 6). Na forma clássica virilizante simples, além da produção deficiente de cortisol, ocorre também o aumento na produção de andrógenos desde o início da gestação, causando ambigüidade genital em graus variados, com virilização progressiva pós-natal no gênero feminino. A ambigüidade genital pode variar desde discreta clitoromegalia até uma genitália francamente virilizada, dificultando o diagnóstico sexual pelo exame físico da genitália externa, a não ser pela não palpação de gônadas. Os ovários e útero desenvolvemse normalmente. Quando não há tratamento adequado, pode surgir pilificação pubiana precoce e excessiva, acne e crescimento rápido, com a ressalva de que, apesar do excessivo crescimento inicial, há fusão epifisária precoce e redução da altura final. Além disso, na mulher adulta, pode ocorrer infertilidade e amenorréia. Nos meninos, a genitália externa é normal ao nascimento, mas a exposição contínua a altas taxas de andrógenos, sem tratamento, provoca o aparecimento precoce dos caracteres secundários masculinos, sem aumento correspondente do volume testicular e baixa estatura final ${ }^{(1-6)}$.
A forma perdedora de sal corresponde a cerca de $75 \%$ dos casos de D21-OH, ocorrendo o comprometimento da produção de cortisol e de mineralocorticóides, o que dificulta o balanço eletrolítico do organismo. Esta forma, além dos sinais de virilização descritos anteriormente, pode se manifestar por quadros graves de desidratação hiponatrêmica e hipercalêmica, vômitos, acidose metabólica, choque hipovolêmico e óbito, quando não é instituído o tratamento adequado, até quadros mais leves, nos quais somente são identificados o baixo ganho ponderal e as alterações laboratoriais eletrolíticas ${ }^{(1-6)}$.

Os estudos genéticos, principalmente de biologia molecular, têm contribuído muito para uma melhor e mais ampla compreensão da doença, tornando disponíveis técnicas precisas e eficientes de diagnóstico e tratamento precoce ${ }^{(1-4,9)}$.

Como a HAC por D21-OH segue um padrão de herança autossômica recessiva, a incidência esperada, em uma família com pais heterozigotos para o gene CYP21A2, deveria ser $25 \%$, observando-se maior número de casos em casamentos consangüíneos ${ }^{(2,7-9)}$. No entanto, não se encontram trabalhos na literatura a este respeito. Portanto, o objetivo do presente estudo foi avaliar a freqüência de indivíduos afetados em famílias com HAC por D21-OH, a taxa de consangüinidade entre os genitores, a freqüência de homozigotos em famílias que apresentaram pelo menos um membro afetado e a distribuição das formas clínicas segundo o sexo.

\section{Métodos}

Foram avaliadas todas as famílias com pelo menos um membro afetado e vivo, com diagnóstico clínico, laboratorial e molecular da forma clássica de HAC por D21-OH em acompanhamento no Ambulatório de Endocrinologia Pediátrica do Hospital das Clínicas da Universidade Estadual de Campinas (Unicamp) ${ }^{(10-12)}$, São Paulo. O estudo somente foi realizado após permissão do responsável pelo paciente e com a assinatura do termo de consentimento pós-informado aprovado pelo Comitê de Ética em Pesquisa da Faculdade de Ciências Médicas da Unicamp.

Trata-se de estudo primário, com análise descritiva de casos. A casuística foi composta por 58 famílias, com 79 pacientes afetados: 56 (70\%) perdedores de sal e $23(30 \%)$ com a forma virilizante simples. Dos 79 pacientes afetados, 67 estavam vivos e 12 mortos, 35 eram masculinos e 44 femininos.

Foram avaliadas as seguintes variáveis em relação ao caso índice: sexo, presença de consangüinidade entre os pais (quando 
Tabela 1 - Distribuição dos dados das 58 famílias com HAC por 21-OHD de acordo com a forma da doença, sexo e sobrevivência dos afetados

\begin{tabular}{lccccc}
\hline \multirow{2}{*}{ Sexo } & \multicolumn{3}{c}{ PS } & \multicolumn{3}{c}{ VS } \\
\cline { 2 - 6 } & $\mathbf{M}$ & $\mathbf{F}$ & $\mathbf{M}$ & $\mathbf{F}$ & Total \\
\hline Vivos afetados & 19 & 25 & 10 & 13 & 67 \\
Mortos afetados & 6 & 6 & 0 & 0 & 12 \\
Total & $\mathbf{2 5}$ & $\mathbf{3 1}$ & $\mathbf{1 0}$ & $\mathbf{1 3}$ & $\mathbf{7 9}$ \\
\hline
\end{tabular}

PS - perdedores de sal; VS - virilizantes simples; M - masculino; $\mathrm{F}$ - feminino

Tabela 2 - Número total de indivíduos (afetados ou não por HAC por 21-OHD), número de indivíduos afetados (vivos ou não) por irmandade e presença de consangüinidade relatada pelos pais

\begin{tabular}{cccc|cccc|cccc}
\hline $\mathbf{F}$ & $\mathbf{T}$ & $\mathbf{A}$ & $\mathbf{C}$ & $\mathbf{F}$ & $\mathbf{T}$ & $\mathbf{A}$ & $\mathbf{C}$ & $\mathbf{F}$ & $\mathbf{T}$ & $\mathbf{A}$ & $\mathbf{C}$ \\
\hline 1 & 1 & 1 & - & 21 & 2 & 1 & + & 41 & 2 & 1 & - \\
2 & 1 & 1 & - & 22 & 2 & 1 & - & 42 & 2 & 1 & - \\
3 & 1 & 1 & - & 23 & 2 & 1 & - & 43 & 2 & 1 & - \\
4 & 1 & 1 & - & 24 & 3 & 1 & - & 44 & 2 & 1 & - \\
5 & 1 & 1 & - & 25 & 3 & 1 & - & 45 & 2 & 1 & - \\
6 & 1 & 1 & + & 26 & 3 & 1 & - & 46 & 2 & 2 & - \\
7 & 1 & 1 & + & 27 & 3 & 2 & - & 47 & 2 & 1 & - \\
8 & 2 & 2 & + & 28 & 3 & 2 & + & 48 & 2 & 1 & - \\
9 & 2 & 1 & - & 29 & 3 & 1 & - & 49 & 3 & 1 & - \\
10 & 2 & 1 & - & 30 & 4 & 3 & + & 50 & 3 & 1 & - \\
11 & 2 & 1 & - & 31 & 4 & 2 & - & 51 & 3 & 2 & + \\
12 & 2 & 1 & - & 32 & 5 & 1 & - & 52 & 5 & 4 & - \\
13 & 2 & 1 & - & 33 & 5 & 1 & + & 53 & 4 & 2 & - \\
14 & 2 & 1 & - & 34 & 7 & 3 & - & 54 & 4 & 2 & - \\
15 & 2 & 1 & - & 35 & 1 & 1 & - & 55 & 4 & 3 & + \\
16 & 2 & 1 & - & 36 & 1 & 1 & - & 56 & 4 & 2 & - \\
17 & 2 & 1 & - & 37 & 1 & 1 & - & 57 & 5 & 2 & - \\
18 & 2 & 1 & - & 38 & 1 & 1 & - & 58 & 8 & 3 & - \\
19 & 2 & 1 & - & 39 & 1 & 1 & - & & & & \\
20 & 2 & 1 & + & 40 & 1 & 1 & - & & & & \\
Total & & & & & & & & $\mathbf{1 4 7}$ & $\mathbf{7 9}$ & $\mathbf{1 0 ( + )}$ \\
\hline
\end{tabular}

$\mathrm{F}$ - família avaliada; $\mathrm{T}$ - total de indivíduos na irmandade; $\mathrm{A}$ - número de afetados na irmandade; $\mathrm{C}$ - presença de consangüinidade referida pela família

Tabela 3 - Alterações moleculares encontradas nos indivíduos vivos afetados das 58 famílias com HAC por 21-OHD, freqüência de homozigotos observada e presença de consangüinidade referida pelas famílias

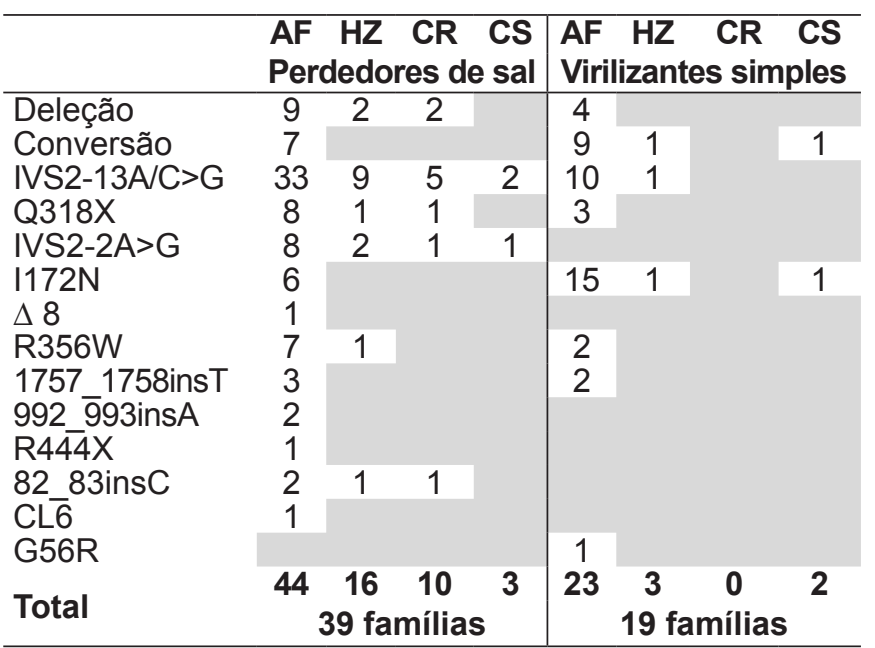

$\mathrm{AF}$ - alelo afetado; $\mathrm{HZ}$ - homozigoto; $\mathrm{CR}$ - consangüinidade referida pela família; CS - consangüinidade suspeita pela alteração molecular em homozigose os pais informavam parentesco até terceiro grau); número e sexo de irmãos, vivos ou não; número de irmãos afetados com doença comprovada; definição na irmandade da forma clínica da doença. Os critérios de inclusão dos irmãos falecidos como afetados constituíram na existência de dados investigativos anteriores à morte ou se o óbito tivesse ocorrido por desidratação ou por choque hipovolêmico nas quatro primeiras semanas de vida ${ }^{(1-6)}$.

Para averiguar a freqüência de indivíduos portadores de HAC por D21-OH foi utilizada a técnica de seleção truncada. A seleção é definida como truncada quando é feita a partir de famílias com pelo menos um indivíduo afetado, não levando em consideração a possibilidade de existir famílias com pais heterozigotos que tenham somente filhos não afetados. Para análise da freqüência de indivíduos afetados foi utilizada a técnica de Haldane com averiguação simples, ou seja, a partir de indivíduos encaminhados por doença e não por averiguação completa feita na comunidade em geral. Para avaliar a heterogeneidade na distribuição de indivíduos afetados entre as irmandades foi utilizada a técnica de Hogben ${ }^{(13)}$.

Os dados foram apresentados em tabelas e utilizouse o teste do qui-quadrado, com nível de significância inferior a 0,05 .

\section{Resultados}

Não foi observada diferença estatisticamente significante na proporção de pacientes masculinos e femininos para as duas formas clínicas $\left(\chi^{2}=0,01 ; p=0,92\right)$, conforme Tabela 1. Na Tabela 2, são apresentados os dados de cada uma das 58 famílias referentes ao número total de filhos (vivos ou não), número de afetados (vivos ou não) e presença de consangüinidade relatada pelos pais.

A Tabela 3 mostra os dados moleculares das 58 famílias estudadas, de acordo com a forma clínica da doença (perdedora de sal ou virilizante simples). Nos dez pacientes (todos perdedores de sal) nos quais os genitores haviam referido consangüinidade, houve detecção de mutações no gene CYP21A2 em homozigose, o que confirma a consangüinidade. Além disso, em mais cinco famílias (três perdedoras de sal e duas com a forma virilizante simples), nas quais não havia história clínica de consangüinidade, os achados moleculares de homozigose levantaram suspeita de consangüinidade entre os pais.

A Tabela 4 mostra os dados das 58 famílias estudadas, excluindo as famílias com um afetado, pois apresentam variância igual a zero. Nesta tabela, são apresentados o número de indivíduos por irmandade, o número observado 
Tabela 4 - Análise dos dados das 58 famílias com HAC por 21-OHD para aplicação da técnica de Hogben (13)

\begin{tabular}{lccccc}
\hline $\mathbf{N}$ & $\mathbf{f}$ & $\mathbf{a}$ & $\mathbf{a}_{\mathbf{e}}$ & $\boldsymbol{\sigma}^{\mathbf{2}}$ & $\mathbf{X}^{\mathbf{2}}=(\mathbf{a}-\mathbf{a e})^{2} / \boldsymbol{\sigma}^{\mathbf{2}}$ \\
\hline 2 & 24 & 26 & $24 \times 1,143=27,432$ & $24 \times 0,122=2,928$ & 0,700 \\
3 & 9 & 12 & $9 \times 1,297=11,673$ & $9 \times 0,263=2,367$ & 0,045 \\
4 & 6 & 14 & $6 \times 1,463=8,778$ & $6 \times 0,420=2,520$ & 10,821 \\
5 & 4 & 8 & $4 \times 1,639=6,556$ & $4 \times 0,592=2,368$ & 0,880 \\
7 & 1 & 3 & $1 \times 2,020=2,020$ & $1 \times 0,970=0,970$ & 0,990 \\
8 & 1 & 3 & $1 \times 2,222=2,222$ & $1 \times 1,172=1,172$ & 0,516 \\
Total & $\mathbf{4 5}$ & $\mathbf{6 6}$ & $\mathbf{5 8 , 6 8 1}$ & $\mathbf{1 2 , 3 2 5}$ & $\mathbf{1 3 , 9 5 2}$ \\
\hline
\end{tabular}

$\mathrm{n}$ - número de indivíduos nas irmandades; $\mathrm{f}$ - número de irmandades; a - número observado de indivíduos afetados; ae - número esperado de indivíduos afetados; $\sigma^{2}$-variância; $\mathrm{X}^{2}$ - valor do qui-quadrado

de indivíduos afetados, o número esperado de indivíduos afetados, a variância e o qui-quadrado pela técnica de Hogben ${ }^{(13)}$ para o cálculo da heterogeneidade da distribuição de casos nas irmandades. Os resultados mostram $\chi_{(4)}^{2}=9,61$, com $0,02<p<0,05$. Sendo assim, por esta técnica, a amostra apresentou distribuição não homogênea de indivíduos afetados entre as irmandades.

A Tabela 5 apresenta os dados de indivíduos afetados por irmandade nas 58 famílias avaliadas e os cálculos necessários para a aplicação da técnica proposta por Haldane. Para corrigir a interferência causada pela averiguação simples, o autor propõe que seja retirado um indivíduo afetado por família estudada ${ }^{(13)}$. Os resultados mostraram $X^{2}=1,73$, com $0,20<p<0,10$. Desta forma, por meio desta técnica, a presente amostra apresentou distribuição compatível com doença monogênica, com padrão de herança autossômica recessiva.

\section{Discussão}

As principais características das anomalias com padrão de herança autossômica recessiva serão discutidas em relação aos resultados obtidos no presente estudo para a forma clássica de HAC por D21-OH.

O reconhecimento de fenótipos recessivos determinados por genes localizados em autossomos é relativamente fácil quando se trata de doenças hereditárias, pois, apesar das numerosas condições que apresentam este padrão, elas geralmente ocorrem em uma freqüência muito baixa na população. Não parece ser este o caso da HAC por D21-OH, porque, dependendo da população estudada e dos métodos de diagnóstico, a freqüência da forma clássica atinge de 1 em 10.000 a 1 em 15.000 nascimentos. Portanto, a freqüência de um alelo seria de aproximadamente 1 em cada 50 a 60 indivíduos $\operatorname{sadios}^{(2,3,7,8)}$. Este estudo não objetiva comprovar esta freqüência, já que não tem características epidemiológicas.
Tabela 5 - Análise dos dados das 58 famílias com HAC por 21-OHD para aplicação da técnica de Haldane ${ }^{(13)}$

\begin{tabular}{lcccccc}
\hline $\mathbf{N}$ & $\mathbf{f}$ & $\mathbf{F n}$ & $\mathbf{a}$ & $\mathbf{a}-\mathbf{f}$ & $\mathbf{f n}-\mathbf{a}$ & $\mathbf{( a - f ) + ( f n - a )}$ \\
\hline 1 & 13 & 13 & 13 & - & - & - \\
2 & 24 & 48 & 26 & 2 & 22 & 24 \\
3 & 9 & 27 & 12 & 3 & 15 & 18 \\
4 & 6 & 24 & 14 & 8 & 10 & 18 \\
5 & 4 & 20 & 8 & 4 & 12 & 16 \\
7 & 1 & 7 & 3 & 2 & 4 & 6 \\
8 & 1 & 8 & 3 & 2 & 5 & 7 \\
Total & $\mathbf{5 8}$ & $\mathbf{1 4 7}$ & $\mathbf{7 9}$ & $\mathbf{2 1}$ & $\mathbf{6 8}$ & $\mathbf{8 9}$ \\
\hline
\end{tabular}

$\mathrm{n}$ - número de indivíduos nas irmandades; $\mathrm{f}$ - número de irmandades; a - número observado de indivíduos com HCA por 21-OHD

Devido à raridade dos alelos autossômicos recessivos, a freqüência de indivíduos que apresentam tais genes é muito baixa, surgindo com maior probabilidade na prole de casais consangüíneos, posto que é mais provável ocorrer a herança de um alelo raro a partir de um ancestral comum do que na população geral. Um dos critérios para reconhecer uma doença com padrão de herança autossômica recessiva consiste em verificar se existe ocorrência maior de casamentos consangüíneos entre genitores de indivíduos afetados do que na população geral. Por exemplo, algumas doenças de herança autossômica recessiva como Tay-Sachs (27 a 53\%), ictiose congênita (30 a 40\%), xeroderma pigmentar (20 a 26\%), albinismo hereditário (18 a 24\%) e fenilcetonúria (12 a 15\%) apresentam alta freqüência de casamentos consangüíneos ${ }^{(13)}$. Em estudo realizado recentemente no Centro de Assistência Integral a Saúde da Mulher da Unicamp, foi encontrada uma taxa de $3 \%$ de consangüinidade entre os pais de recém-nascidos com diversas anomalias congênitas ${ }^{(14)}$. Na presente amostra de 58 famílias com a forma clássica de HAC por D21-OH, observouse freqüência de consangüinidade que variou de 10/58 (17\%, consangüinidade relatada pelos genitores) a 15/58 (26\%, homozigose observada no estudo molecular) entre os genitores sadios cujas crianças eram afetadas. No entanto, estudos moleculares mais avançados com haplótipos do gene CYP21A2 
seriam necessários para confirmar se a origem é comum das mutações em homozigose na prole de casais sem relato de consangüinidade. Portanto, apesar da alta freqüência do gene descrita na literatura, a taxa de consangüinidade também parece ser alta para a forma clássica de HAC por D21-OH.

Um segundo critério para reconhecer doenças com padrão de herança autossômica recessiva, também decorrente da raridade dos alelos determinantes, consiste em verificar se tanto os genitores quanto os ancestrais distantes de um indivíduo afetado são sadios ou assintomáticos. Este dado não pôde ser comprovado no presente estudo, pois o mesmo partiu da pesquisa de indivíduos afetados com pais não afetados. No entanto, diante da freqüência do alelo da forma clássica de HAC por D21-OH descrita na literatura e pelo fato de que a doença, de uma forma geral, não impede a função reprodutiva, não seria estranho encontrar filhos doentes com pelo menos um dos pais afetado ${ }^{(3,7,15)}$.

Partindo do princípio designado no segundo critério, o terceiro seria verificar a proporção de indivíduos afetados na irmandade de pessoas com doenças com padrão de herança autossômica recessiva, provenientes de casais heterozigotos sem doença. Esta proporção deve ser de $1 / 4$ ou $25 \%$, sem desvios significativos. Contudo, na forma clássica de HAC por D21-OH existe a possibilidade de um dos genitores ser afetado (homozigoto) e o outro não-afetado (hetrozigoto). Neste caso, a proporção de filhos homozigotos eleva-se para $50 \%$ ou $1 / 2$. Além disso, se ambos os genitores forem afetados, a proporção de filhos afetados atinge $100 \%$ ou $1 / 1$. No presente estudo, somente as irmandades provenientes de pais não afetados foram avaliadas. Deste modo, a proporção de

\section{Referências bibliográficas}

1. White PC, Speiser PW. Congenital adrenal hyperplasia due to 21 -hydroxylase deficiency. Endocr Rev 2000;21:245-91.

2. Speiser PW. Congenital adrenal hyperplasia owing to 21-hydroxylase deficiency. Endocrinol Metab Clin North Am 2001;30:31-59.

3. New MI. Diagnosis and management of congenital adrenal hyperplasia. Annu Rev Med 1998;49:311-28.

4. Merke DP, Bornstein SR. Congenital adrenal hyperplasia. Lancet 2005;365:2125-36.

5. Lemos-Marini SHV, De Mello MP. Hiperplasia congênita das supra-renais. In: Maciel-Guerra AT, Guerra-Júnior G, editores. Menino ou menina? Os distúrbios da diferenciação do sexo. São Paulo: Manole; 2002. p. 61-81.

6. Lemos-Marini SHV, Baptista MTM, Guerra-Júnior G. Hiperplasia congênita das supra-renais. In: Monte O, Longui CA, Calliari LE, Kochi C, editores. Endocrinologia para o pediatra. São Paulo: Atheneu; 2006. p. 269-76.

7. Merke D, Kabbani M. Congenital adrenal hyperplasia: epidemiology, management and practical drug treatment. Paediatr Drugs 2001;3:599-611.

8. McKusik VA. OMIM: On line mendelian inheritance in man [homepage na Internet] [citado em Fevereiro 7, 2007]. Disponível em: http://www.ncbi.nlm.nih.gov/entrez/ dispomim. cgi?id $=201910$

9. Forest MG. Recent advances in the diagnosis and management of congenital adrenal hyperplasia due to 21-hydroxylase deficiency. Hum Reprod Update 2004; 10:469-85.

10. Araújo M, Sanches MR, Suzuki LA, Guerra G Jr, Farah, SB, De Mello MP. Molecular analysis of CYP-21 and C4 genes in Brazilian families with the classical forms of the steroid 21-hydroxylase deficiency. Braz J Med Biol Res 1996;29:1-13. filhos afetados deveria ser próxima de $25 \%$. A análise feita pela técnica de Haldane ${ }^{(13)}$ mostrou que esta proporção não diferiu significativamente de $25 \%$, ficando em $23,5 \%$.

Um quarto critério para identificar doenças com padrão de herança autossômica recessiva consiste em verificar a proporção de indivíduos afetados e sadios de acordo com o sexo, na irmandade. Esta proporção deve ser semelhante, pois se trata de uma doença com herança autossômica recessiva e não de uma doença com herança ligada aos cromossomos sexuais. Nosso estudo encontrou proporção igual entre os sexos, diferente do citado na maioria dos estudos feitos antes do estabelecimento da triagem neonatal para a HAC. Com a falta de diagnóstico precoce dos homens perdedores de sal, os mesmos morriam mais do que as mulheres, as quais são diagnosticadas pela ambigüidade genital, fazendo predominar as mulheres entre os perdedores de sal ${ }^{(16-18)}$.

Portanto, o estudo realizado permite confirmar que a forma clássica de HAC por D21-OH apresenta as características de doença com padrão de herança autossômica recessiva, porém, com peculiaridades próprias decorrentes da frequiência do alelo afetado e das características diagnósticas no recém-nascido.

\section{Agradecimentos}

Ao Conselho Nacional de Desenvolvimento Científico e Tecnológico (CNPq) pelas bolsas de iniciação científica e à Fundação de Amparo à Pesquisa do Estado de São Paulo (Fapesp) pela bolsa de mestrado.
11. Paulino LC, Araújo M, Guerra G Jr, Marini SH, De Mello MP. Mutation distribution and CYP21/C4 locus variability in Brazilian families with the classical form of the 21-hydroxylase deficiency. Acta Paediatr 1999;88:275-83.

12. Lau IF, Soardi FC, Lemos-Marini SH, Guerra G Jr, Baptista MT, De Mello MP. $\mathrm{H} 28+\mathrm{C}$ insertion in the CYP21 gene: a novel frameshift mutation in a Brazilian patient with the classical form of 21-hydroxylase deficiency. J Clin Endocrinol Metab 2001;86:5877-80.

13. Beiguelman B. Genética Médica: dinâmica dos genes nas famílias e nas populações. São Paulo: Edart; 1977.

14. Moreno CA, Cavalcanti DP. Consangüinidade parental em uma amostra de recém-nascidos no CAISM. Anais do XI Congresso Interno de Iniciação Científica da Unicamp; 2003, Setembro, 25-26; Campinas: B036.

15. White PC, Speiser PW. Long-term consequences of childhood-onset congenital adrenal hyperplasia. Best Pract Res Clin Endocrinol Metab 2002; 16:273-88.

16. Trakakis E, Laggas D, Salamalekis E, Creatsas G. 21-hydroxylase deficiency: from molecular to clinical presentation. J Endocrinol Invest 2005;28:187-92.

17. Strnadova KA, Votava F, Lebl J, Muhl A, Item C, Bodamer OA et al. Prevalence of congenital adrenal hyperplasia among sudden infant death in the Czech Republic and Austria. Eur J Pediatr 2007;166:1-4.

18. New MI. An update of congenital adrenal hyperplasia. Ann N Y Acad Sci 2004;1038:14-43. 